Instructions for authors, subscriptions and further details:

http://brac.hipatiapress.com

\title{
Forma y Color: La Grisalla en la Pintura; Aproximación a un Procedimiento Inadvertido
}

Andrés Torres Carceller ${ }^{1}$

1) Universitat de Barcelona. España

Date of publication: June 3rd, 2015

Edition period: June 2015 - October 2015

To cite this article: Torres Carceller, A. (2015). Forma y Color: La grisalla en la pintura; aproximación a un procedimiento inadvertido. Barcelona, Research, Art, Creation, 3(2), 179-200. doi: 10.17583/brac.2015.1350

To link this article: http://dx.doi.org/10.17583/brac.2015.1350

\section{PLEASE SCROLL DOWN FOR ARTICLE}

The terms and conditions of use, except where otherwise noted, are related to the Open Journal System and to Creative Commons Attribution License (CCBY). The indication must be expressly stated when necessary. 
BRAC - Barcelona Research Art Creation. Vol. 3 No. 2, June 2015, pp. 179-200

\section{Form and Color: The Grisaille in Painting; an Approximation to an Inadvertent Procedure}

Andrés Torres Carceller

University of Barcelona

(Received: 14 Desember 2014; Accepted: 13 May 2015; Published: 3 June 2015)

\section{Abstract}

Although the grisaille term is associated with monochrome painting is also a method of polychrome paint, with the difference that divides the work process into two distinct phases, treating separately the form and color. Despite its current lack of knowledge, this variant was one of the favorite methods of painters from the Middle Ages until the seventeenth century; and remains practiced until today. This article aims to clarify this dark side of the grisaille, sequencing their work process (and its variants), exposing its most significant features; verify the versatility of its principle, adapted for painting stained glass, illustrations, prints, enamels and even photography and cinema. And identify its origins and main features that been gone adopted over time.

Keywords: grisaille; painting; outline; painting procedures; painting methods 
BRAC - Barcelona Research Art Creation. Vol. 3 No. 2, June 2015, pp. 179-200

\section{Forma y Color: La Grisalla en la Pintura; Aproximación a un Procedimiento Inadvertido}

Andrés Torres Carceller

Universidad de Barcelona

(Recibido: 14 Diciembre 2014; Aceptado: 13 Mayo 2014; Publicado: 3 Junio 2015)

\section{Resumen}

Aunque se asocie el término grisalla con pintura monocroma, también es un procedimiento de pintura policroma, con la particularidad que divide el proceso de trabajo en dos fases diferenciadas, tratando por separado la forma y el color. Pese a su actual desconocimiento, esta variante ha sido uno de los métodos predilectos de los pintores desde la Edad Media hasta el siglo XVII; manteniéndose viva hasta nuestros días. En este artículo pretendemos aclarar esta cara oculta de la grisalla, secuenciando su proceso de trabajo -y sus variantes-, exponiendo sus rasgos más significativos; constatando la transversalidad de su principio, al ser adaptado a la pintura de vitrales, ilustraciones, grabados, esmaltes e incluso la fotografía y el cine. Así como señalar sus orígenes y las principales características que ha ido adoptando a lo largo del tiempo.

Palabras clave: grisalla, pintura, bosquejo, procedimientos pictóricos, métodos pictóricos 


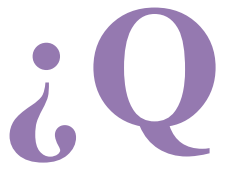

ué es la Grisalla ${ }^{1}$ ? Fácil pregunta, pero difícil respuesta. Es un término poco preciso, cuyo significado completo es poco conocido. Las diferentes acepciones que hoy agrupa el término grisalla, vienen utilizándose desde antes de que fuera nombrado como tal en diversas técnicas, todas ellas relacionadas con la pintura. Cuando nos referimos a pintura, en lo primero que pensamos es en los cuadros, la pintura de caballete. Pero la pintura engloba una gran cantidad de técnicas, en unos casos de manera clara, como podría ser la ilustración y en otros, como las vidrieras, el esmalte o algunas técnicas de grabado, no tanto. En todas ellas se utiliza, constituyendo incluso -en la vidriera y el esmalte- una rama muy importante. Por tanto podemos establecer como punto de inicio que la grisalla está unida a la pintura. Siendo una de las muchas innovaciones procedimentales que se han venido sucediendo en su historia, adaptándose y facilitando cambios estilísticos y metodológicos.

La Grisalla empieza a emerger en la Edad Media, primero, como respuesta a la necesidad de artistas y artesanos de representar las formas con cierto aspecto volumétrico, y después, desarrollándose a la par de la pintura naturalista. Los pintores ya no se conforman con arquetipos, empiezan a interesarse por el dibujo y a experimentar con los materiales. Ya no bastaba con que la imagen representara, sino que debía parecerse al motivo. El trabajo plano y tosco medieval dejó paso a la delicadeza y a lo volumétrico. Mientras que el estilo dibujístico ve las lineas, las nuevas maneras pictóricas se centran en los volúmenes y las masas. La Grisalla empieza a ser algo cotidiano en los talleres de los pintores y artesanos góticos, siendo utilizada en un principio para las encarnaduras y paulatinamente ir ampliando su uso, extendiéndola finalmente a un gran número de elementos. Aún así, pasado un tiempo, su ámbito habitual continuarán siendo las encarnaduras. Puntualizando los volúmenes monocromos con sombreados marrones. Como nada es eterno, la Grisalla empezará a mostrar síntomas de agotamiento en el siglo XVIII, cuando la técnica directa empiece a ganar terreno, terminará por desbancarla en el siglo siguiente como el método preferido por los pintores. Pese a ello la Grisalla no se extinguirá, agazapándose en la pintura naturalista y realista, e incluso siendo empleada por pintores de Vanguardia (surrealistas, cubistas y noucentistas).

Desde la segunda mitad del siglo XX, la grisalla apenas ha suscitado interés 
-ni tan siquiera por parte de los pintores-, quedando relegada del primer plano y por tanto cayendo en el desconocimiento. Sin haber desaparecido por completo, su empleo es escaso y se limita -principalmente- a pinturas figurativas.

Lo primero que pensará el lector al leer la palabra grisalla es en pinturas ejecutadas en blanco y negro, el propio término conduce a relacionarlo con la pintura monocroma. Además el propio término grisalla es poco preciso, englobando una serie de procedimientos, similares pero no idénticos, adaptados a lo largo del tiempo en diferentes técnicas.

Aún así, podemos diferenciar dos variantes, la más conocida -pero menos practicada- que se centra exclusivamente en valores de claroscuro, y la más extendida y practicada, donde se trabajan tanto los valores lumínicos y cromáticos.

Esta diferenciación queda reflejada en la pluralidad de definiciones sobre la grisalla, donde podemos constatar como, las obras generalistas se limitan al primer grupo:

Diccionario de la RAE ( $22^{\mathrm{a}}$ edición):

Grisalla (Del fr. grisaille)

1.- Pintura realizada con diferentes tonos de gris, blanco y negro, que imita relieves escultóricos o recrea espacios arquitectónicos.

Diccionario del Institut d'Estudis Catalans (segunda edición):

1.- Pintura executada només amb diverses tonalitats de gris.

2.- Representació figurada en un vitrall obtinguda pintant amb diversos tons de gris.

Fatás y Borrás (1993, p.124): “Composición pintada exclusivamente a base de la gama del gris, del blanco y del negro, imitando el efecto del bajo relieve. Se usó mucho en el siglo XVI".

Estas definiciones muestran una versión sesgada, desviándose del concepto principal, centrándose en una práctica pictórica de carácter inferior y mucho menos extendida. La Grisalla es algo más que una simple imitación de la piedra o de molduras en trampantojo. Entendemos que estos procedimientos, realizados exclusivamente con grises, se asocien con ella, pero la vertiente con mayor significación tanto histórica como artística es la que ha sido empleada ininterrumpidamente desde -al menos- el siglo XIII hasta nuestros días. En ninguna de las anteriores definiciones se nombra el color, es más, se niega su presencia; cuando el color es una parte esencial, sin color no puede haber Grisalla. En cierta medida, el hecho de que la vertiente principal de la grisalla, se trate de un procedimiento pictórico cuyo resultado final, sea la suma de 
sucesivas capas sobrepuestas que ocultan parcial o casi totalmente el trabajo inferior de claroscuro, dificulta su identificación en obras acabadas -y en buen estado de conservación-, lo que sin duda ha contribuido a su desconocimiento generalizado.

Para encontrar definiciones rigurosas que se adecuen al principio en el que se fundamenta la Grisalla debemos acudir -salvo contadas excepciones- a manuales y tratados de pintura:

Enciclopedia Británica (2007):

Painting technique by which an image is executed entirely in shades of gray and usually severely modeled to create the illusion of sculpture, especially relief (...). Among glass painters, grisaille is the name of a gray, vitreous pigment used in the art of colouring glass for stained glass. In French, grisaille has also come to mean any painting technique in which translucent oil colours are laid over a monotone underpainting. In the grisaille enamel painting technique, pulverized white vitreous enamel is made into a paste by mixing it with water, turpentine, oil of lavender, or petroleum oil and is then applied to a dark enamel ground, usually coloured black or blue. Lighter areas of the design are thickly painted, while the gray areas are obtained by painting with thinner coats to allow the dark background colour to tone the white enamel pigment (...) The technique was also popular with some 20th-century painters, including Alfred Leslie and Chuck Close.

Pedrola (1999, p.188): "Cuando se estudian solamente los valores monocromos y el color se aplica posteriormente en otras sesiones".

Mayer (1985, p.588):

Todos los métodos de pintura que no empleaban una técnica simple y directa; más específicamente, se refiere al método de pintar elaborando todo el modelado en blanco y negro, o en otros tonos simples y contrastantes, y aplicando encima color transparente en veladuras o capas finas. También es el nombre de un pigmento empleado para pintar cristales.

Murray (1978, p.258):

Es el nombre dado a una pintura enteramente monocroma, ejecutada con tonos grises. (...) Se puede hacer una grisaille en sí, como obra 
decorativa, o para que sirva de modelo a un grabador, o también puede ser la grisaille la primera etapa en la realización de una pintura al óleo.

\section{Villarquide (2004, p.11):}

Las luces están resueltas en la primera fase del trabajo, y el color y modelado definitivo, en una segunda etapa. La primera etapa define las formas y las luces mediante el encaje y el sombreado con carbón, al modo de los dibujos, o mediante grises* aglutinados con el mismo medio utilizado en la película pictórica. Posteriormente se "colorean" estas formas con tintes locales aplicados sin trabajar el conjunto de la obra al tiempo, sino rellenando zonas independientes. Los detalles se añaden al final para definir el conjunto. En este sistema de trabajo, pues, las últimas capas son dependientes y se ven facilitadas por las primeras. (...) El resultado sólo es apreciable una vez concluida la obra.

*[nota de la propia autora] Son las llamadas grisallas: pinturas sólo a base de gris (blanco + negro) o con un color (blanco + negro + ocre $\mathrm{u}$ otro). Formaban la base monocroma del cuadro estableciendo los claroscuros que después se coloreaban).

\section{Gallego y Sanz (2001, p.435):}

Distribución pictórica elemental de las áreas de luz y sombra mediante la indicación de éstas últimas con un color gris. Antiguamente, solía utilizarse como pintura figurativa inferior, sobre la cual se daba el colorido politonal definitivo. A veces, se enriquecía su claroscuro con algunas coloraciones grises y, más raramente, con algún ocre pardo.

Pino (2005, p.110): [Refiriéndose sólo para la pintura al óleo y estableciendo tres fases en la ejecución de una pintura: Dibujo, Mancha y Empaste; su descripción es la siguiente]

El manchado de una obra se lleva a cabo en dos etapas: la primera es la grisalla y la segunda aplicación de tonos y matices claros y medios. Con un solo color, el dominante en toda la composición, se hace una valoración de tono o grisalla. Es un estudio monocromático del conjunto para dar las primeras soluciones. Sobre esta capa monocroma inicial, se procede a aplicar luego los tonos y matices correspondientes a cada objeto. 
Doerner (1986, pp.182-183): [Sin llamarlo Grisalla sino pintura por capas, lo describe de la siguiente manera]

Fundada en el principio de la división del trabajo. (...) En la capa inferior se dan el dibujo (forma), el modelado (sombreado) y tan sólo una ligera indicación del colorido. Hay pintores que hacen esta primera capa completa con todos los detalles, mientras otros se limitan a indicar las grandes superficies sin buscar el efecto de los detalles. (...) Este trabajo preliminar lo realizaban con frecuencia otros colaboradores para ganar tiempo y sin apoyar sobre el color ninguna parte y el maestro lo aprovechaba para realizar una pintura directa abreviada. (...) De manera que al dar cada una no se perdiera el efecto de la anterior y los tonos del fondo contribuyeran a las sombras y transiciones. (...) $\mathrm{La}$ armonía, el tono unitario del cuadro, es, sin duda, más fácil de lograr con una capa inferior uniforme que si está compuesta de colores.

Estas definiciones muestran como la Grisalla es mucho más que una pintura para imitar bajorrelieves y esculturas, adoptando una concepción pragmática del proceso de ejecución de la obra, creando las formas mediante el claroscuro, para después colorearlas mediante veladuras. Empleando una gama de grises porque es el tono ideal para crear volúmenes, ¿que mayor contraste se puede conseguir que con blanco y negro? Además es el que menos variará el color de las sucesivas capas de color. Atendiéndonos a las diferentes definiciones, la relación entre palabras como monocromo y grisalla parece difusa, ¿pero son la misma cosa?

\section{Diferencia entre Pintura Monocroma y Grisalla}

Comúnmente confundidas como sinónimos, aunque compartan similitudes, no son lo mismo. La pintura monocroma se centra únicamente en representar los volúmenes. Es una pintura de rápida ejecución, pintada con técnica directa, trabajando desde el primer momento sobre el efecto final de la obra, tratando de alcanzarlo por el camino más corto, si es posible al primer intento. Su realización es mucho más sencilla, ya que al trabajar con un único color -simplemente más claro o más oscuro- no existe el peligro de que los distintos colores se enturbien, por lo que se puede insistir todo lo que se quiera, corrigiendo sobre la marcha en una única sesión.

Una variante de la pintura monocroma es la de claroscuro, que al igual que 
la monocroma se centra en los valores lumínicos, con la diferencia de utilizar -además del blanco y el negro- diferentes tonos de una gama similar. Como podrían ser -por ejemplo- los colores terrosos: ocres, sienas, pardos,...

Pese a representar ambas la acepción más conocida de la grisalla, estos procedimientos se utilizaron principalmente en pinturas decorativas, generalmente de carácter menor, y hoy en día su práctica es muy minoritaria.

La Grisalla es un perfeccionamiento de la pintura monocroma, comparte sus inicios, pero con una intencionalidad muy diferente. Mientras la pintura monocroma se limita al claroscuro, la Grisalla continúa el trabajo, sobreponiendo superficies de color. Debido a lo cual las diferencias son evidentes entre una y otra, y no solo en el aspecto final, pues incluso en la elaboración de las formas en claroscuro, las de la Grisalla están realizadas con mayor contraste, ya que las veladuras de color -por muy ligeras que seantamizan los matices del modelado, por lo que, igual que una pintura colocada a gran distancia del espectador, los contrastes deben exagerarse, prediciendo las consecuencias de las posteriores capas de coloración.

La Grisalla es una manera racional de entender la pintura, sistematizando su proceso, dividiéndolo en dos fases diferenciadas e independientes, elaborando la forma y el colorido por separado.

Esta separación es el principio fundamental de la Grisalla, y pese a la natural evolución que sufre su metodología desde la Edad Media hasta la actualidad, es su rasgo identificativo, que se ha mantenido a través del tiempo, siendo también adoptado en otras disciplinas como la fotografía y el cine, cuando en sus inicios se iluminaron a mano, e incluso -para el cine- se idearon diferentes variantes para colorear los fotogramas con estarcido de forma seriada, como fue el sistema que Segundo de Chomón desarrolló entre 1902 y 1906, en el cual se utilizaban las propias copias positivadas para crear las plantillas -como en la técnica de grabado al claroscuro- se empleaba una película por color, recortando las zonas que se querían colorear, llegando a utilizar hasta siete colores distintos. El inconveniente del sistema de Chomón era que al desgelitinizar la película -indispensable para hacerla transparente y facilitar la posterior aplicación del color- suponía que -en el proceso químico- la película redujera levemente su tamaño, provocando que la coloración no fuera del todo precisa.

El desglose de la pintura en diversas partes ha sido un tema recurrente en los escritos de los pintores, y aunque no aludan directamente a la Grisalla, podemos ver reflejado su principio en sus divisiones. Battista Alberti en De Pictura (1434) divide la pintura en tres partes: Contorno, Composición y 
Adumbración, y afirma que "con el blanco y el negro se expresan en la pintura las luces y las sombras, y que los demás colores vienen a ser la materia a que se agregan los varios accidentes de la claridad u oscuridad" (Garriga, 1983, p.36). Para Francesco Lancillotti -Tractato di Pictura (1509)- la pintura se compone de Dibujo, Colorido, Composición e Invención (Schlosser, 1993, p.176). Que Paolo Pino reduce en su Dialogo di pittura (1548) a Dibujo, Invención y Colorido (Ibídem, p.213). Armenini (1998, pp.58 y 59) en 1587 la divide en cinco partes partes: "il dissegno, il lume [e] l'ombre, il colorito et il compimento", de las cuales las luces y sombras, logran "che tutto ciò che si dissegna si rappresenta a gli occhi in modo qual si vede essere le cose spiccate e vere". Roger de Piles en su Dialogo sobre el color (1673) diferencia entre el color local y el claroscuro, que aunque en la naturaleza vengan juntos deben ser separados por el artista (Fernández; Basegodas, 1983, p.197).

En la literatura artística española también existe esta división, aunque Palomino y Pacheco la limitan -principalmente- a Dibujar y Colorir; división análoga a la de la Grisalla. El mismo Pacheco (1866, p.18) nos advierte que "cuando los de esta profesion sean excelentes y milagrosos en colorir, si no tienen dibujo no tienen la forma de la pintura, y consiguientemente son privados de la parte sustancial de ella". Regón de Silva (1985, p.74) mantiene -más de un siglo después (en 1786)- una división similar, diferenciando entre dibujo, claroscuro y colorido.

El principio fundamental de la Grisalla se ajusta a estas divisiones -es más, podríamos decir que es a la inversa, siendo éstas fruto del empleo de la Grisalla.-, fraccionando la ejecución de la pintura en dos partes separadas, pero interdependientes: la fase de claroscuro y la fase de coloración.

Por lo general, la Grisalla se ejecuta sobre un soporte imprimado con una tonalidad media, normalmente terrosa, que facilita la unidad tonal de la obra, así como la posibilidad de producir gamas de gris óptico.

En la fase de claroscuro se crean las formas exclusivamente mediante gradaciones lumínicas, ya advertía Barocchi que "Lo chiaroscuro è il piu presto e piu util modo, a il migliore disegnare" (Holanda, 2008, p.92), generalmente grises, aunque también se pueden utilizar otros colores, según el interés del pintor. Si queremos -por ejemplo- que en el resultado final aparezca un amarillo vibrante, no realizaremos la pintura inferior con azules, porque el resultado sabemos que no será el deseado, en cambio si nos interesa un rojo intenso, el fondo puede pintarse con amarillos.

Como en todos los métodos de pintura, cada pintor acaba creando el suyo propio, existiendo innumerables variables. A grosso modo diferenciamos dos 
maneras diferentes de realizar la primera fase:

Monocroma: Es la más frecuente, quizá por ser la manera más básica y sencilla, desarrollando el trabajo con gradaciones de un único color, que habitualmente -y por las razones anteriormente comentadas- es el gris. Siendo el método original de pintura con Grisalla, que ha ido evolucionando a lo largo de la historia. En un principio (siglo XV), condicionados por la pintura al temple, las gradaciones se ejecutaban con pincelada plumeada, elaborando el claroscuro mediante tratteggio; obrando mediante iluminación, es decir, resaltando las luces sobre un fondo de tonalidad media ${ }^{2}$. La introducción de los aceites secantes como aglutinante, permitirá un súbito progreso, posibilitando que los pintores puedan optar por un mayor abanico de posibilidades técnicas, propiciando que con el paso del tiempo la técnica pictórica se singularice, y mientras unos pintores fundan los tonos mediante esfumados, otros los apliquen de manera yuxtapuesta mediante centelleantes pinceladas. Asimismo también evolucionará desde las meras iluminaciones sobre fondos medios, hasta extender la fase de claroscuro a todo el área de encarnadura (siglos XV y XVI). A partir de entonces -y hasta nuestros días-, los pintores optarán por diferentes opciones, sin que ninguna se imponga claramente, conviviendo al mismo tiempo variaciones que combinan características de ambos métodos ${ }^{3}$.

El hecho de que mayoritariamente se haya optado por elaborar la fase de claroscuro con gamas monocromas, no solo queda constatado en las propias pinturas $^{4}$, existiendo alusiones a su proceso o utilización en tratados artísticos desde el siglo XV, siendo el periodo comprendido entre el XVI y el XVII donde los pintores dejaron más referencias por escrito.

Entre las que conocemos -no dudamos que existan más-, citamos algunas como constatación histórica y muestra del empleo de la fase de claroscuro monocroma, principal indicativo de la Grisalla.

Leon Battista Alberti (1996, pp.130 y 131) escribe que:

Los pintores deberían, primeramente, estudiar con todo cuidado las luces y las sombras (...). En cuanto a representar la luz con el color blanco y la sombra con el negro. (...) Primeramente modificará el color de la superficie usando el blanco o el negro, lo que resulte necesario, aplicándolo como un suave rocío hasta alcanzar el margen. (...) Aplicando un poco de blanco con tanta moderación como sea posible en el lugar adecuado dentro del contorno de la superficie, e igualmente añadir algo de negro en el lugar opuesto. (...) Así, con mucho cuidado y poco a poco pueden aumentar el blanco y el negro hasta alcanzar el efecto requerido. 
También Battista Armenini (1998, p.163) recomienda que "para hacer las mezclas de claroscuro (...) molido el carbón y purificado el blanco, se hacen de estos dos extremos al menos tres intermedios, cada uno más claro que el otro".

En la bibliografía española del Siglo de Oro, la fase de claroscuro monocroma queda registrada en las disertaciones sobre el bosquejo -manchar o meter colores-, donde se esbozaba la configuración de la tridimensionalidad de las formas, Bruquetas (2002, p.318) expone que:

El bosquejo podía variar en función de que el dibujo fuera más o menos ajustado. Algunos pintores utilizaban el bosquejo para alterar el dibujo, o simplemente saltárselo, utilizando mezclas monócromas de blancos, negros y grises. (...) Con el bosquejo, tanto si era en grisalla o con todos los colores, se pretendía encajar los puntos de máxima luz, los medios tonos y las sombras.

Cuando Pacheco (1990, p.482) describe el proceso de elaboración de una pintura, tras haber realizado el dibujo, nos informa que se prosigue de varias maneras, pues "unos bosquexan con poco blanco y negro, o con blanco y carmin revuelto con sombra de italia, y es modo fácil y acomodado para los que no tienen mucha resolución y certeza, (...) mudando lo que les parece y se borra y revuelve uno y otro más facilmente". Aunque él es partidario de la pintura directa ${ }^{5}$. Jusepe Martínez $(1988$, pp. 86, 87) lo recomienda cuando trata sobre el precepto de la unión -fundamental para la consonancia de la obra-, escribiendo que el "pintor ha de proceder en sus dibujos y modelos, y para conseguir la unión (...), ha de hacerlos de blanco y negro (...). Porque si se vale de colores en el modelo, se confundirá fácilmente, pues tal vez enamorado de la belleza del colorido no se hará lugar para ejecutar con toda certeza su claro y oscuro. Esto he visto en los más peritos pintores". Asimismo lo recomienda Carducho (1979, p.247), al confesar "que el colorido es tan amable y apetecible, por lo que tiene de hermoso y alegre, (...) menos estimada es por los doctos (...). Las colores tan poderosas, encubren muchos yerros, y así acostumbraron los que exactamente pretendieron conducir sus obras, hacerlas, ó bosquejarlas primero de blanco y negro, por huir del hechizo de las colores, para que el entendimiento más desembarazadamente jugase y corriese, sin que la vista le barajase el concepto con el deleite de las colores".

En la misma linea, Palomino de Castro $(1988$, pp.150, 152) también aconseja bosquejar "haciendo los claros de blanco, y negro de carbón, en el 
grado más, o menos obscuro", para posteriormente "quebrantarla con un poco de ocre claro, y algún tanto de bermellón; y luego hacer otra más rosadita"; mientras que para las sombras "es buena tinta para la mancha general de los oscuros (...) el blanco y negro, quebrantado con un poquito de ocre, y carmín”.

En esta muestra comprobamos como justifican la utilización del blanco y el negro en esta fase inicial por su idoneidad para valorar el claroscuro, además, permite realizar el trabajo sin la distracción del color, que gracias a esta base puede aplicarse posteriormente con mayor libertad.

Policroma: La vertiente más extendida cuando se emplea más de un color en la fase de claroscuro, es la combinación -generalmente por separado- de gamas terrosas y grises ${ }^{6}$. Esta variante aparece en el siglo XV, utilizándose tanto en la pintura al temple como al óleo. Los ejemplos más significativos de este método, son las dos obras inacabadas San Jerónimo (Museos Vaticanos) y Adoración de los Reyes (Uffizi) de Leonardo, abandonadas en plena realización de la fase de claroscuro; la primera en una fase inicial, utilizando exclusivamente tonos terrosos y la segunda con valoraciones más elaboradas con blanco y negro ${ }^{7}$.

Aunque muy minoritaria -y practicada exclusivamente desde la segunda mitad del siglo XX-, también existe la posibilidad de trabajar con diversos colores en la primera fase, manteniendo la división entre forma y color. Elaborando el claroscuro con colores elegidos por su interacción con los que los superpondrán en la fase de coloración, variando premeditadamente un color específico en un área concreta.

Este método, también puede realizarse ejecutando la fase de claroscuro de forma monocroma, tiñendo posteriormente partes concretas con veladuras del color deseado.

A partir de mediados del siglo XV, y como consecuencia directa de la introducción de la pintura al óleo, empieza a realizarse tras la fase de claroscuro un sombreado terroso -tierra sombra o siena tostada- en las encarnaciones, que a la vez que aumenta el contraste lumínico oscureciendo las sombras, también las colorea. Aplicando posteriormente las tintas de encarnación exclusivamente en las zonas iluminadas.

A diferencia de la anterior modalidad, donde se combinan gamas terrosas y grises sin solución de continuidad junto al dibujo inicial, el sombreado terroso se aplica con posterioridad; la fase de claroscuro crea las formas, mientras que el sombreado terroso las acentúa.

Fase de coloración: Sobre el trabajo de claroscuro, el procedimiento de la Grisalla da color a las formas previamente pintadas mediante transparencias, 
obteniendo resultados que nada tienen que ver con la pintura directa. La gran ventaja de la Grisalla, es que las formas se pueden conseguir con el grado de detalle que deseemos, para después despreocupándonos de la forma -ya plasmada-, aplicar libremente el color. La Grisalla es fundamentalmente buena definidora de volúmenes, capaz de graduar el color con una gran precisión, logrando resultados imposibles de obtener con técnica directa.

A diferencia de la primera fase, la manera de ejecutar la segunda es fundamental, modificando sustancialmente su aspecto ulterior. No se obtendrá el mismo resultado mediante veladuras que con medias pastas que resten la influencia del fondo, o incluso obrando puntualmente con pinceladas cargadas de materia que ocultan por completo la fase anterior. Generalizando, podemos diferenciar dos maneras diferentes de aplicar el color:

Coloreada: Cuando el color se aplica mediante veladuras uniformes, que tiñen las formas de la fase de claroscuro, pudiendo modular los matices del color por transparencia, variando su disolución.

Pintada: Son aquellas que modificando la opacidad de las tintas de coloración matizan o modifican las formas de la fase de claroscuro. Por lo general están pintadas mediante técnica mixta, que aprovecha la fase de claroscuro como una referencia sobre la que aplicar el color con mayor libertad, modificando en parte la fase anterior obrando mediante veladuras, restregones, empastes...

Por tanto, mientras la pintura Monocroma solo se interesa por las formas, creadas mediante el claroscuro; la Grisalla abarca tanto las formas como el color, con la singularidad -respecto a otros procedimientos- que lo hace de forma separada.

El empleo de transparencias requiere predecir lo que sucederá, no se trabaja directamente sobre la imagen final, sino que la obra se va construyendo estrato por estrato. Con técnica directa, forma y color se deben elaborar al mismo tiempo, lo cual dificulta una finalización uniforme. En el proceso de pintura por capas que adopta la Grisalla, la obra se ejecuta por fases acumulativas, de cuya correcta suma depende el resultado final. Debido a lo cual, pese a trabajar la forma y el color de forma separada, ambas fases mantienen una relación directa, complementándose la una con la otra. Esto conduce a que su interdependencia produzca una regla de compensación en la elaboración de las fases, que por lo general es desigual, lo que provoca que cuando una está más elaborada, la otra lo esté menos. Por ejemplo si el grado de elaboración de la fase de claroscuro es elevado, la fase de coloración se realizará de forma simple. Y al contrario, teniendo que finalizar la creación de las formas al mismo tiempo que se añaden los colores. En este sentido Doerner (1986, p.183) ya 
escribía que: "Una capa inferior correctamente aplicada sirve también para simplificar la ejecución de la superior, que debe ser en lo posible directa, descargando con ello el trabajo".

Esta metodología hoy resulta extraña por poco frecuente, pero debemos tener en cuenta que es el resultado de una evolución desarrollada durante siglos por numerosos pintores -siendo el método habitual en Europa durante los siglos XIV y XVII, manteniendo bastantes adeptos hasta la mitad del siglo pasado-.

\section{Entorno a sus Orígenes}

Es prácticamente imposible establecer su origen exacto -tanto cronológico, técnico e incluso geográfico-. Aun así podemos señalar que durante el siglo XIII empiezan a aparecer indicios claros del empleo del principio de la Grisalla en distintas zonas de Europa, utilizando maneras de proceder muy similares -en cada una de las técnicas- ${ }^{8}$. Esta diversidad hace inabarcable el poder concretar con absoluta exactitud un origen concreto, pero demuestra la versatilidad de un procedimiento que fue adoptado de manera natural en puntos diversos por artesanos y artistas sin contacto entre si.

No podemos obviar que la Grisalla ya fue empleada en la pintura del Imperio Romano, perfectamente visible -por ejemplo- en el fresco de la villa de Boscoreale (Museo Arqueológico de Nápoles). Desconocemos si se trata de un uso puntual o si estaba más extendido. La obra fechada hacia el año 40 d.c. demuestra que la Grisalla fue utilizada mucho antes de su redescubrimiento en la Edad Media, reafirmándose así como un método de pintura práctico y racional, lo cual encaja perfectamente con el pensamiento pragmático romano. De esta forma, si especulamos sobre los inicios de la Grisalla debemos tener en cuenta este antecedente. No podemos asegurar con rotundidad que exista una continuidad en el tiempo, permitiendo una relación directa -por lejana que fuera- entre la Grisalla romana y la Grisalla que reaparece a partir de la Edad Media. Está claro que la tradición de la pintura romana del Imperio Occidental desapareció con su caída, dejando afortunadamente restos, que quizás pudieran influenciar a generaciones futuras de pintores. Por otra parte, si el uso de la Grisalla se extendió también al Imperio Oriental, podría explicar la profunda penetración de la Grisalla en la pintura bizantina, adoptándola para la pintura de Iconos, que probablemente ayudó a la (re)aparición de la Grisalla $^{9}$ y su posterior difusión desde Italia en la Edad Media. Los primeros ejemplos claros de Grisalla en la Corona de Aragón -frontal de El Salvador 
(Museu Lleida Diocesà i Comarcal)- provienen de obras de marcado carácter bizantino. Lo cual podría indicar que la Grisalla pudo mantenerse viva en el Imperio Oriental, permitiendo -dicho con cautela- una continuidad directa del empleo de la Grisalla desde la pintura romana hasta nuestros días.

Para Plinio (2002), la pintura se origina a partir del delineado del contorno de la sombra de un hombre, desarrollándose hacia la pintura monocroma, hasta alcanzar en su tiempo la representación de la luz y la sombra, lo que hizo destacar los colores. De esta forma, desde los supuestos orígenes de la pintura en la historia, ésta ha sido creada por medio de contrastes lumínicos, mucho antes de que el poder de atracción de los colores y su vistosidad le restara protagonismo, "las fuentes escritas ponen de manifiesto que esta variedad (cromática) se contempla en términos de luminosidad, de brillo, de esplendor, concibiendo el color como los intervalos de una escala entre dos conceptos antagónicos: la luz y la oscuridad, el blanco y el negro" (González, 2005, p.211).

El ser humano porta en su ADN la atracción por las formas, en los primeros años de vida, cuando empezamos a interesarnos -por puro instinto- por el dibujo, el color es algo totalmente secundario ${ }^{10}$. Para Cézanne el gris era el color dominante en la naturaleza (Salabert, 1985, p.70). El juego que nos brinda en cuestión de valores es inmenso, en todo su espectro abarca desde el blanco puro, hasta el negro más denso. Para la física, que estudia los colores luz, sólo se consideran como tal las radiaciones visibles para el ojo humano, es decir, las comprendidas entre el ultravioleta y el infrarrojo, siendo perceptibles en este espectro toda la gama de rojos, púrpuras, azules, cianes, verdes y amarillos. La captación del blanco es el resultado de la suma de las frecuencias y el negro la ausencia de luz. "El entero movimiento del blanco al negro ofrece una imagen de la distancia gigantesca entre los dos polos -trayecto que cubre todas las etapas desde la fuente de lo visible hasta sus últimos confines o lucha abierta de los extremos que se entrechocan-" (Klee, 2007, p.64). Como el blanco y el negro no son considerados como colores, el gris tampoco debe serlo. Sea cual sea la nomenclatura, siempre los encontraremos como extremos opuestos, mientras que los grises representarán los valores lumínicos intermedios. Por su neutralidad cromática, el gris es el color más apropiado para representar los volúmenes. Las teorías de la física respecto al color, no hacen más que confirmar la excelente intuición de los pintores precedentes a éstas, que simplemente por la práctica del oficio, eligieron la gama de grises para desarrollar la Grisalla. Además tanto el negro como el blanco, son y han sido -junto a otros pigmentos de origen mineral- los colores 
más accesibles y de menor coste. Sus pigmentos se encuentran de una u otra forma prácticamente en todo el mundo. Ambos han sido imprescindibles para la pintura, "el blanco y el negro como condimento de todos" escribe Armenini (1999, p.86), además sólo se podían obtener en su estado puro:

non sono composti, nè si possono comporre per via di mistione d'altri colori, nero, bianco; benchè questi non sono messi fra'colori, perchè l'uno è tenebre, l'altro è luce, cioè l'uno è privazione, e l'altro è generativo: ma io non li voglio per questo lasciare indietro, perchè in pittura sono li principali, conciossiachè la pittura sia composta d'ombre, e di lumi, cioè di chiaro e oscuro (Da Vinci, 1804, p.75).

Desde la antigüedad existen referencias sobre ambos. El albayalde (blanco de plomo) ya lo mencionan Plinio y Vitrubio; así como el negro de marfil y el de humo.

Desde el punto de vista del lenguaje, las connotaciones que rodean al gris son siempre negativas: triste, lánguido, apagado, aburrido, monótono; siendo lo contrario de vivo, alegre. Para Lomazzo, "el color gris, compuesto de blanco y negro, significa paciencia, esperanza, consolidación y simplicidad; pero el que tiende más hacia el negro, sequía, pobreza enemistad, desesperación" (Garriga, 1983, p.327). Para gran parte de los pintores, el gris no es un color como los otros, es el rechazo del color, un color sin dignidad. Es muy frecuente en nuestros días escuchar la recomendación de no utilizar el color negro, según dicen porque ensucia el resto de colores, cuando todos los colores tienen esa misma facultad, todo depende del uso que se les dé -o se les sepa dar-, atribuyéndole en muchos casos los problemas de una mala praxis, ya decía Rizi "poco importa que el pintor sea elocuente, si los pinceles son mudos" (de Castro, 1988, p.363). Lo mismo ocurre con el blanco, pues su sobreutilización, enharina las pinturas cuando se mezcla físicamente con los colores, mientras que el mismo color extendido sobre una superficie blanca apenas pierde saturación, exactamente como ocurre con el negro.

\section{La Importancia del Estudio de la Metodología Artística}

El gran lastre que arrastra actualmente la Grisalla, es su desconocimiento. Pese a la inmensa cantidad de obras existentes, localizables prácticamente en todos los museos del mundo que conserven pinturas occidentales realizadas 
entre el siglo XVI y el XVIII ${ }^{11}$, mostrando al espectador -en muchas de ellasla fase de claroscuro de forma directa. Pues a pesar de todo ello, la Grisalla en la actualidad no existe, no tiene presencia alguna más allá de en algunos talleres y en el testimonio mudo de las obras que atesoran los museos. La Grisalla es mucho más que un método para la reproducción de relieves, lo cual teniendo en cuenta las obras, ya no solo en términos cualitativos, sino simplemente cuantitativos, esta variante es menos que una anécdota que ha devorado en el imaginario colectivo el todo del término Grisalla.

Al desenfoque del termino ha contribuido también la falta de interés por la propia técnica pictórica, por el proceso de trabajo desarrollado por los artistas, que es fundamental para comprender las obras. Contempladas generalmente desde una única perspectiva, que nos ofrece una visión tuerta -y por tanto incompleta-. Por supuesto es necesario el trabajo de recopilación e interpretación de datos relativos a los artistas y sus obras desde el ámbito histórico, pero este discurso no puede ocupar todo el espacio. Cualquiera que consulte bibliografía sobre pintura, comprobará como la parte relativa a sus métodos es mínima, siendo tratada de forma rigurosa casi exclusivamente por restauradores. Pero sin minusvalorar su pulso quirúrgico, los pintores somos los que mejor conocemos los entresijos de todo lo relativo al proceso de creación de las obras y es nuestro deber contribuir didácticamente al debate, facilitando su comprensión para personas ajenas a la práctica artística y aumentando el interés por la magia que transcurre desde que se inicia una pintura, hasta que se decide darla por concluida.

Casos tan habituales como el cambio de rumbo de una obra, haciendo modificaciones durante su realización es -y ha sido- lo más normal, forma parte del propio proceso ${ }^{12}$. No puede ser este uno -si no el más- de los temas estrella en relación con los procedimientos pictóricos. El énfasis sobre las modificaciones del dibujo inicial o los pentimentos posteriores nos parece exagerado, tratándose de una cuestión banal, alejada de los aspectos medulares que nos ayudarán a conocer y comprender mejor las obras, que es su proceso de ejecución, en sí, y no las modificaciones sufridas sobre la marcha producto de lo imprevisible del oficio ${ }^{13}$.

André Lhote se centra en los materiales, afirmando que "nuestros aceites, esencias, gomas y colores son totalmente diferentes de los que todavía había en el siglo XVIII, incluso un pintor genial no podría realizar hoy día el equivalente de aquel arte (el de Tiziano y Veronés) cuyo poder expresivo reside enteramente en su material pictórico" (Gilson, 1961, p.49). Evidentemente no dudamos de la importancia que tienen los materiales, pero pensamos que 
también es un error plantear el tema exclusivamente desde esta perspectiva, pues la verdadera cuestión diferencial es la metodología, aquí radica la esencia de la técnica, pues los soportes, las herramientas y el material, pese a las evidentes diferencias, son en lo sustancial los mismos; el diseño de un caballete, del bastidor, de los pinceles o la paleta poco ha cambiado, y al fin y al cabo la pintura, colores son. Lo importante -más allá de emulaciones- es comprender su proceso de trabajo, conocer como han actuado para conseguir sus resultados.

En este sentido tampoco nos parece relevante la hipótesis de Hockney (2002), sobre el secreto de los antiguos pintores, defendiendo que lo recóndito de su técnica, que les permitía obtener sus preciados resultados era la utilización de la cámara oscura; recordamos las palabras de Leonardo (Da Vinci, 1980, p.140), donde afirma que:

Es mas difícil sombrear una figura que dibujar los contornos de la misma; el modelado requiere reflexión y estudio largo. Los perfiles pueden ser dibujados con auxilio de un cristal colocado entre el ojo y el objeto, pero semejante expediente no sirve para dibujar sombras.

Pues el hecho de poder calcar el dibujo, no condiciona sustancialmente el resultado de una pintura -a no ser que el pintor no sepa dibujar-. Es más, desde la aparición de los proyectores de diapositivas y con los actuales digitales, existe la misma posibilidad -con menos limitaciones- de calcar imágenes sobre el soporte, sin que por ello asegure obtener resultados como los de los antiguos maestros. Porque su esencia se encuentra -insistimos- en su metodología, en la manera en como trabajan y que pasos siguen para completar sus pinturas.

Las obras no solo muestran colores, personajes, sucesos o emociones, dicen mucho más porque: "El método de trabajo de un pintor y los recursos técnicos de los que se vale en cada momento para la creación de sus cuadros son misterios que, una vez desaparecido el artista, han quedado atrapados y guardados en cada una de las obras que realizó"(Garrido, 2003, p.93), conservando su secreto para aquel que lo quiera ver. El problema es que generalmente nos quedamos en la superficie. 


\section{BRAC - Barcelona Research Art Creation, 3(2)}

\section{Notas}

1 A lo largo del artículo escribimos "Grisalla" con mayúscula cuando nos referimos al procedimiento pictórico que divide el proceso de elaboración en dos fases, fase de claroscuro y fase de coloración; diferenciándola así de la "grisalla" en general, con todas sus acepciones. ${ }^{2}$ En este periodo existen numerosas obras, que debido al deterioro o perdida parcial de las capas de coloración, nos permiten observar con claridad la fase de claroscuro, uno claro ejemplo es el rostro de la figura central de san Esteban del retablo del Maestro de Badalona (Museu Nacional d'Art de Catalunya).

${ }^{3}$ La variante flamenca -al ser esta escuela la primera que extiende la fase de claroscuro a todo el área de encarnadura-, que podemos -por ejemplo- observar en la pintura anónima de Niños mendigos (Museu Nacional d'Art de Catalunya); o, con una ejecución dispar, sin preocuparse por la unión, en la Epifanía de Francisco Herrera "el viejo".

${ }^{4}$ Pese a tratarse de una pintura ejecutada por capas, ocultando las ulteriores a las primeras, el paso del tiempo o la propia voluntad del pintor, permiten observar en la actualidad la fase de claroscuro en un gran número de obras, como es el caso de las obras de el Greco, uno de los artistas que han utilizado la Grisalla de manera más explícita, véase por ejemplo La visión de san Juan (Metropolitan Museum of Art).

5 "Yo tengo más acertado comenzar a bosquexar de todos colores, por las cabezas y carnes de las figuras y más si son del natural". De ahí que la menosprecie como un método para pintores con poca resolución, justo por una de sus ventajas, que es poder poner y quitar "más fácilmente" (Pacheco, 1990, p.482).

${ }^{6}$ La gran difusión de la Grisalla en los talleres góticos, propició que surgieran maneras que aprovechaban su principio, como por ejemplo el efecto cangianti o changeant, que consistía en el realce de las luces con blanco o amarillo y la acentuación de las sombras mediante negro, violeta o verde oscuro. Aunque la variante con una mayor continuidad en el tiempo e incluso con una gran extensión geográfica fue el verdacho. Que sustituía a los grises o tierras de las partes sombreadas, sobre el cual se iluminaba con blanco o directamente se aplicaban las tintas de encarnación clara. También fue utilizado como fondo, cubriendo uniformemente las áreas de encarnadura sobre la imprimación. Sin embargo -salvo contados casos- el verdacho apenas valora el claroscuro, siendo más bien una base.

${ }^{7}$ En su tratado (Da Vinci, 1950, p.301) empieza a describir este procedimiento, aunque debido, según el propio Leonardo, a lo extenso del tema, no termina de explicarlo, emplazándonos a un próximo libro dedicado a la práctica y la teoría; lamentablemente, -parece ser- que fue una de las tantas ideas que no llegó a materializar.

${ }^{8}$ Como muestran -por ejemplo- los frescos de Santa Cecilia in Trastevere de Pietro Cavallini, la Madonna del Bordone de Coppo di Marcovaldo en pintura, donde ejecutan un esbozo previo del modelado con tonos tierra o incluso con grises, e incluso obras del renovador Giotto como el Crucifijo de Rimini, con una valoración lumínica más refinada; las vidrieras de Namburgo y Chartres, con una pintura con grisalla fundamentalmente dibujística, pero con medios tonos para las zonas sombreadas; o -en los inicios del S.XIV- las miniaturas de Jean Pucelle en el Libro de Horas de Jeanne d'Evreux (Metropolitan Museum; The Cloisters Collection).

${ }^{9}$ Dos excelentes muestras del influjo medieval bizantino, son las pinturas murales de los monasterios de Sopocani y Mileseva (S.XIII).

${ }^{10}$ Léase Lowenfeld, V. (1977). Desarrollo de la capacidad creadora. Buenos Aires: Kapelusz; Luquet, G. H. (1978). El dibujo infantil. Barcelona: Médica y Técnica; o Gardner, H. (2005). Arte mente y cerebro: una aproximación cognitiva a la creatividad. Barcelona: Paidós. pp.177194. 
${ }^{11}$ Recordamos la anécdota (leyenda) de Miguel Ángel y Rafael, sucedida cuando un amigo del florentino quiso observar las obras del joven pintor que tanto éxito estaba cosechando recién llegado a Roma. Rafael lo recibió en su estudio, y durante toda la tarde pudo observar como pintaba una cabeza de Anibal Cartaginés, "que borró muchas vezes, haziendo y desaziendo, cuidadoso de executar lo que la mente y el deseo tenia concebido". A su regreso "le preguntó Micael: Y que viste? Respondio: Pocos años, y poco saber; porque en toda la tarde que he estado con él, no ha hecho sino quitar y poner, hazer y borrar: al fin todo era ir tentando, como persona que no sabe, y que a tiento obra. A quien respondio Micaelangel: Haze y borra, quita y pone? Ese sabe, y a ese temo" (Carducho,1979, p.203).

${ }^{12}$ Hay que entender que el proceso de trabajo es libre, por mucho que el pintor parta de una idea inicial, esta no es inalterable ni tiene que estar concluida. A diferencia -por ejemplo- de la de un edificio, donde el arquitecto plasma hasta el más mínimo detalle en su proyecto, el pintor -con o sin proyecto- a medida que da forma física a su idea, puede modificarla repetidas veces, porque su creación y su plasmación van unidas, mientras que un arquitecto no puede empezar la(s) obra(s) pensando $<<$ a medida que lo construyo dejo que el edificio me hable indicándome que dirección tomar $>>$. Sobre este toma y daca, Eisner (2004, p.106) escribe que "en el caso de las artes [plásticas], la persona se deja guiar por la obra. La obra, por así decirlo, también habla, y es el artista quien escucha. La obra que se crea empieza a parecerse más a una conversación que a un monólogo".

\section{Referencias}

Alberti, L. B. (1996). De la pintura. México D.F.: U.N.A.M.

Armenini, G. B. (1998). De'veri precetti della pittura. Turín: Einaudi.

Bruquetas, R. (2002). Técnicas y materiales de la pintura española en los siglos de oro. Madrid: Fundación de apoyo a la historia del arte hispánico. Carducho, V. (1979). Diálogos de la pintura. Madrid: Turner.

Castro, A. P. de (1988). El museo pictórico y la escala óptica. Madrid: Aguilar. Da Vinci, L. (1804). Trattado della pittura. Milán: Società tipográfica de'classici italiani.

Da Vinci, L. (1950). Tratado de pintura. Madrid: Aguilar.

Da Vinci, L. (1980). Tratado de pintura. Madrid: Editora Nacional.

Doerner, M. (1986). Los materiales de pintura y su empleo en el arte. Barcelona: Reverté.

Eisner, E. W. (2004). El arte y la creación de la mente. Barcelona: Paidós.

Fatás, G. y Borrás, G. M. (1993). Diccionario de términos de Arte. Madrid: Alianza.

Fernández, J., y Basegodas, B. (1983). Fuentes y documentos para la historia del arte. Barcelona: Gustavo Gili.

Gallego, R., y Sanz, J. C. (2001). Diccionario akal del color. Tres Cantos: Akal. 
Garrido, C. (2003). Aproximaciones a la técnica de Tiziano. En Falomir, M. (Ed.). Tiziano. Madrid: Museo Nacional del Prado.

Garriga, J. (1983). Fuentes y documentos para la historia del arte. Barcelona: Gustavo Gili.

Gilson, É. (1961). Pintura y realidad. Madrid: Aguilar.

González, J. M. (Coord.). (2005). Introducción al color. Tres Cantos: Akal.

Hockney, D. (2002). El Conocimiento secreto: el redescubrimiento de las

técnicas perdidas de los grandes maestros. Barcelona: Destino.

Holanda, F. de (2008). Del sacar del natural. Madrid: Akal.

Klee, P. (2007). Teoría del arte moderno. Buenos Aires: Cactus.

Mansur, G. et al. (2007). Grisaille. En: Encyclopedia Britannica. Londres: Encyclopedia Britannica.

Martínez, J. (1988). Discursos practicables del nobilísimo arte de la pintura. Madrid: Akal.

Mayer, R. (1985). Materiales y técnicas del arte. Madrid: Herman Blume.

Murray, P., y Murray, L. (1978). Diccionario de Arte y Artistas. Barcelona: Parramon.

Pacheco, F. (1866). Arte de la pintura. Madrid: Imprenta de Manuel Galiano. Pacheco, F. (1990). Arte de la pintura. Madrid: Cátedra.

Pedrola, A. (1999). Materiales, procedimientos y técnicas pictóricas. Barcelona: Ariel.

Pino, G. (2005). Las Artes Plásticas. San José: EUNED.

Plinio, C. (2002) Historia Natural. Madrid: Cátedra.

Regón de Silva, D. A. (1985). La pintura: poema dedicado en tres cantos. Murcia: Caja Murcia.

Salabert, P. (1985). (D)efecto de la pintura. Barcelona: Anthropos.

Schlosser, J. (1993). La literatura artística. Manual de fuentes de la historia moderna del arte. Madrid: Cátedra.

Villarquide, A. (2004). La pintura sobre tela. San Sebastián: Nerea. 
Andrés Torres Carceller: Profesor Asociado en el Departamento de Didáctica de la Educación Visual y Plástica. Universidad de Barcelona.

Contact Address: Facultad de Educación. Universidad de Barcelona. Passeig de la Vall d'Hebron, 171, 08035 Barcelona (España).

E-mail address: andrestorres@ub.edu 